\title{
THE EDITOR'S DESK
}

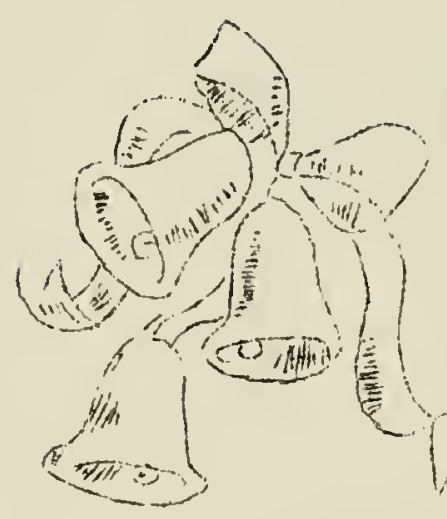

To each of our readers at this time we wish a Merry Christmas, together with the hope that the New Year will bring added happiness in a closer association with Nature and with the countless gifts which she has to bestow.

With this issue of the BLUE JAY you will have received the fourth since we took our place at this Desk. In spite of our many short-comings, we hope that you have en joyed Volume VII. With the active assistance of each reader, we w11l endeavour to make the issues of 1950 much better and a step nearer to that ideal which we feel should be attained in the publication of a Provincial Nature Bulletin.

Now that winter is with us, do not feel that Mother Nature, like the bears and gophers, has gone into hibernation and has nothing to disclose until the warm sun of spring appears again. There will be countless and interesting observations to be made and recorded. Send us an account of them, so that all may enjoy with you those experiences.

Makes a special effort during the last week of the year to participate in the Christmas bird census. In this manner only can records be compiled which will give us an over-all picture of the prevalence and distribution of our residents and winter visitants.

We have been asked several been given the name BIUE JAY, fact that to the majority of our seldom or never seen.

We will agree with Taverner are noisy, mischievous, inquisite less intelligent and alert. Most the latter category; but surely cause of a fancied resemblance. former. No, that was not the

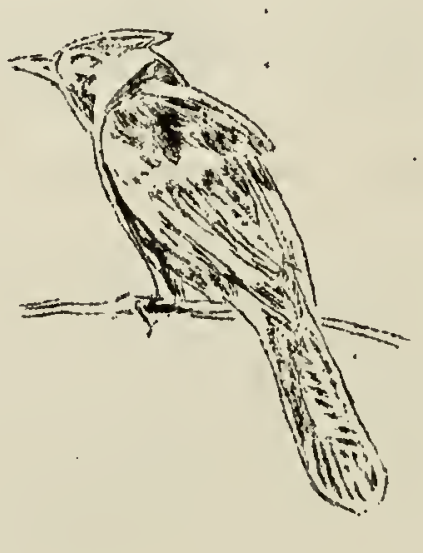

times why this Bulletin has particularly in view of the readers the Blue Jay is

that although these birds clowns, they are nevertheof our members belong to this name was not given beof nature lovers to the reason.

In the second issue of the BLUE JAY, Mrs. Priestly gave the reason. "We chose the name BLUE JAY for our little paper because $1 t$ was "Sammy" Blue Jay, in the Burgess Bedtime Stories who always carried the news to the "Iittle People of the Green Forest and Green Meadows" and "Sammy" has always been a very réal personage to some of us."

We hope that the Bulletin will continue to be a carrier of those intriguing tales of Nature to all who find joy and pleasure in the great out-of-doors. 